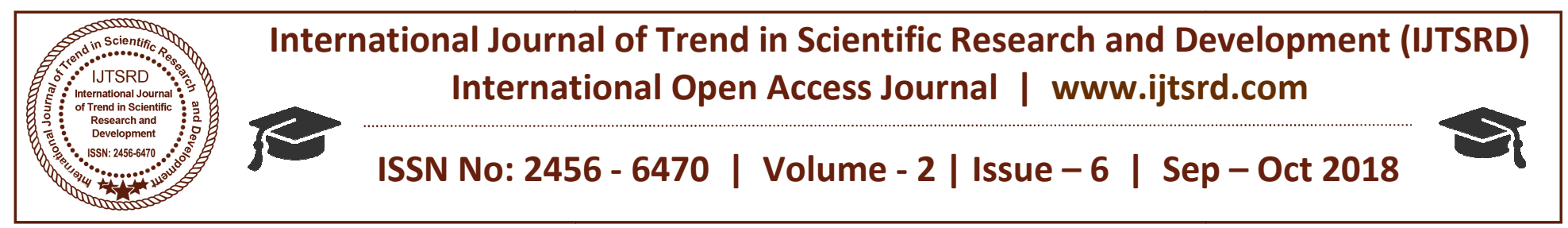

\title{
Investigation on Friction Stirs Welding of Aluminum Alloy and Copper Dissimilar Metals
}

\author{
J. Eswara Kumar ${ }^{1}$, J. Sree Hari ${ }^{2}$, L. Anwesh Kumar ${ }^{3}$ \\ ${ }^{1}$ P.G. Scholar, ${ }^{2}$ Assistant Professor, \\ Sri Venkateswara Institute of Technology, Anantapur, Andhra Pradesh, India
}

\begin{abstract}
The joining of dissimilar Aluminium Alloy and Copper aluminium plates of $5 \mathrm{~mm}$ thickness was carried out by friction stir welding (FSW) technique. Optimum process parameters were obtained for joints using statistical approach. Five different tool designs have been employed to analyse the influence of rotation speed and traverse speed over the micro structural and tensile properties. In FSW technique, the process of welding of the base material, well below its melting temperature, has opened up new trends in producing efficient dissimilar joints. Effect of welding speed on microstructures, hardness distribution and tensile properties of the welded joints were investigated. By varying the process parameters, defect free and high efficiency welded joints were produced. The ratio between tool shoulder diameter and pin diameter is the most dominant factor. From micro structural analysis it is evident that the material placed on the advancing side dominates the nugget region. The hardness in the HAZ of 6061 was found to be minimum, where the welded joints failed during the tensile studies.
\end{abstract}

Keywords: FSW technique, HAZ

\section{INTRODUCTION}

\subsection{Welding}

Welding is a process by which two similar or dissimilar metals may be joined by heating them to suitable temperatures with or without the application of the pressure and without use of filler metal. The filler metal has its melting point either approximately the same as that of the work piece metal or little lower but normally about 430degree centigrade.

During welding the edges of the work piece's to be welded are heated by several ways. Heat may be

derived from electric arc, oxy-acetylene or oxyhydrogen flame, black smith fire or chemical reaction as in case of thermit welding.

\subsubsection{Autogeneos welding:}

Welding consists of those processes in which similar metals are joined with the help of filler rod of same metal. EX: mild steel, cast iron.

\subsubsection{Heterogeneous welding:}

It is a method in which dissimilar metals are joined. The metals being joined are brought up to critical temperature or plastic state and the filler rod is used. The melting point of filler rod less than parent metals for easy melting.

EX: copper<->brass.

\section{Classification of welding}

Welding is classified into two types. They are

$>$ Fusion (or) non pressure welding

$>$ Pressure welding

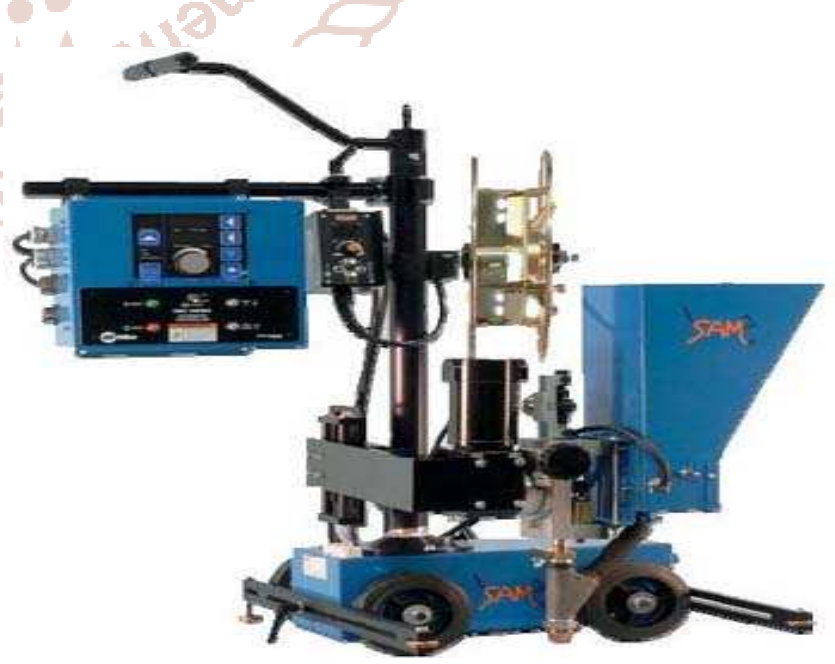

Figure 1: Friction stirs welding 


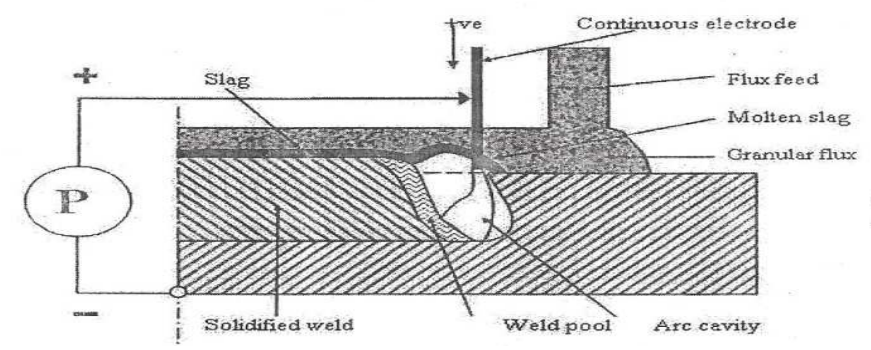

Figure 2: process

Since the arc is completely submerged by the flux there is no irritating arc radiation that is characteristic of the open arc process-welding screens are therefore necessary. The welding flux is never completely consumed so the surplus quantity left can be collected, either by hand or automatically and returned to the flux hopper to be used again. Although semi-automatic submerged arc welding equipment exists and is convenient for certain applications, most submerged arc welding uses fully mechanized welding equipment. One of the main virtues of the submerged arc process is the ease with which it can be incorporated into fully mechanized welding systems to give high deposition rates and consistent weld quality. Weld metal recovery approaches $100 \%$ since losses through spatter are extremely small. Heat losses from the arc are also quite low due to the insulating effect of the flux bed and therefore the thermal efficiency of the process can be as high as $60 \%$ compared with about $25 \%$ for MMA welding.

\section{METHODOLOGY}

There are two tool speeds to be considered in frictionstir welding; how fast the tool rotates and how quickly it traverses the interface. These two parameters have considerable importance and must be chosen with care to ensure a successful and efficient welding cycle. The relationship between the welding speeds and the heat input during welding is complex but, in general, it can be said that increasing the rotation speed or decreasing the traverse speed will result in a hotter weld. In order to produce a successful weld it is necessary that the material surrounding the tool is hot enough to enable the extensive plastic flow required and minimize the forces acting on the tool. If the material is too cool then voids or other flaws may be present in the stir zone and in extreme cases the tool may break. At the other end of the scale excessively high heat input may be detrimental to the final properties of the weld. Theoretically, this could even result in defects due to the liquation of low-meltingpoint phases. These competing demands lead onto the concept of a 'processing window': the range of processing parameters that will produce a good quality weld. Within this window the resulting weld will have a sufficiently high heat input to ensure adequate material plasticity but not so high that the weld properties are excessively reduced.

\section{TOOL TILT AND PLUNGE DEPTH}

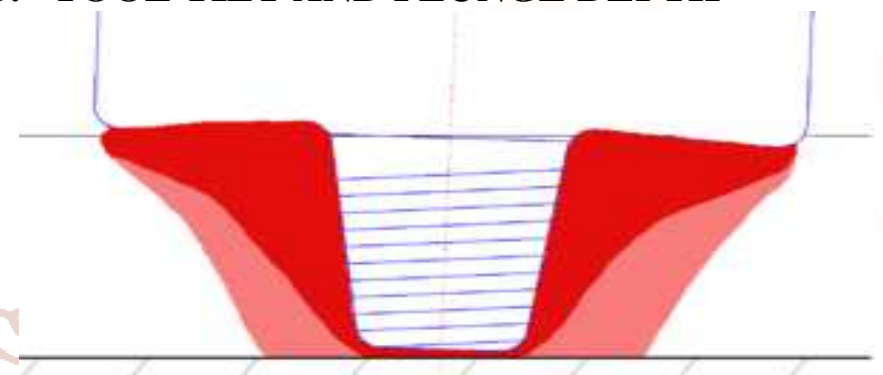

\section{Figure 3: Tool tilt and plunger depth}

A drawing showing the plunge depth and tilt of the tool. The tool is moving to the left. The plunge depth is defined as the depth of the lowest point of the shoulder below the surface of the welded plate and has been found to be a critical parameter for ensuring weld quality. Plunging the shoulder below the plate surface increases the pressure below the tool and helps ensure adequate forging of the material at the rear of the tool. The plunge depth needs to be correctly set, both to ensure the necessary downward pressure is achieved and to ensure that the tool fully penetrates the weld. Given the high loads required the welding machine may deflect and so reduce the plunge depth compared to the nominal setting, which may result in flaws in the weld. On the other hand an excessive plunge depth may result in the pin rubbing on the backing plate surface or a significant under match of the weld thickness compared to the base material. Variable load welders have been developed to automatically compensate for changes in the tool displacement while TWI have demonstrated a roller system that maintains the tool position above the weld plate.

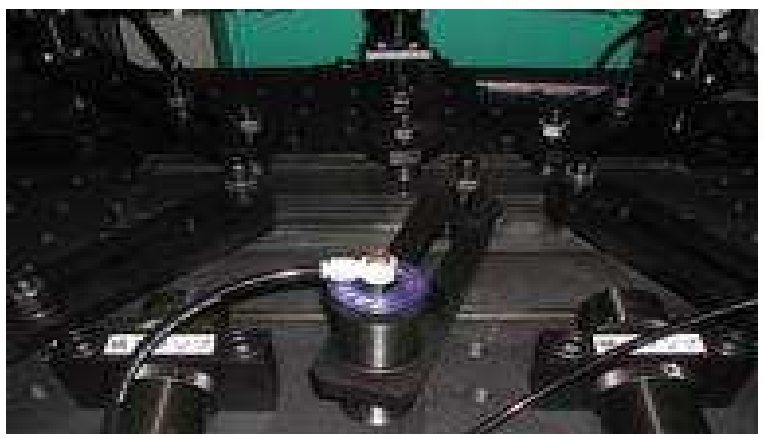




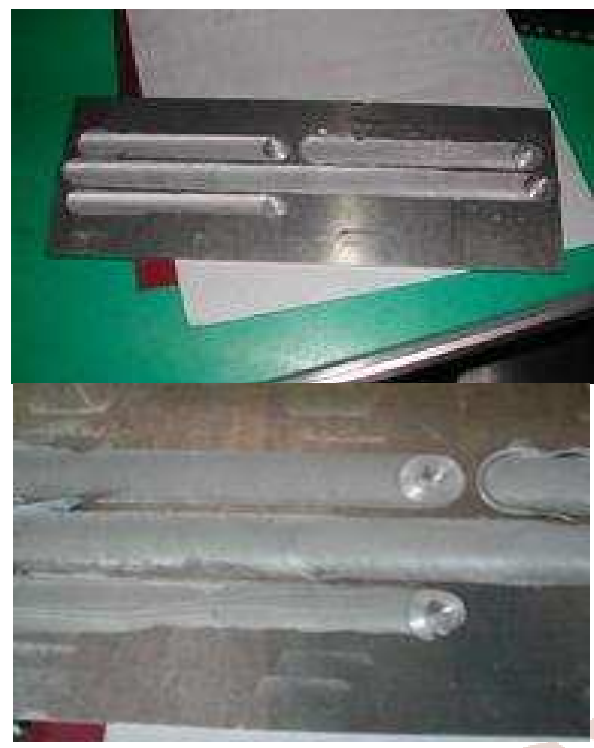

\section{speed vs UTS (MPa)}

$\because 400=750=900$

125.247 .249 .903

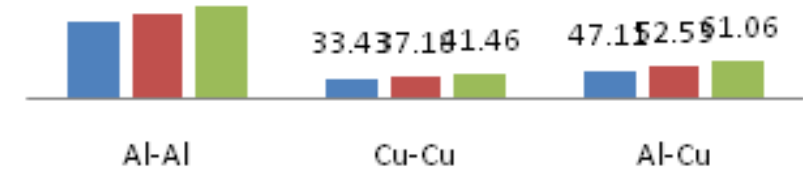

Figure 6: Comparison plot for Friction welded plates

Figure 4: Fixtures and weld

\section{RESULTS AND DISCUSSION}

\subsection{FRICTION STIR WELDING OF}

\section{AA6061-Cu}

Friction stir welding trials were performed using different friction stir welding parameters obtained from literature. The following process parameters (Rotational speed - $800 \mathrm{rpm}$, Welding speed - 40 $\mathrm{mm} /$ minute, Shoulder diameter to pin diameter - 3) were used for friction stir welding to get the defect free good quality welds. Trial and error method were used get these process parameters

\subsubsection{Micro Structure}

The base materials used in the study contained grains elongated in the rolling direction and a large number of eutectic and intermetallic particles. The Thermo Mechanically Affected Zone on either side showed highly deformed grains, with a clearly discernible Stirred zone/Thermo Mechanically Affected Zone and Thermo Mechanically Affected/Heat Affected Zone boundaries. In the Heat Affected Zone (HAZ), on either side of the weld nugget, there were no noticeable changes in the grain structure compared to the respective unaffected base materials

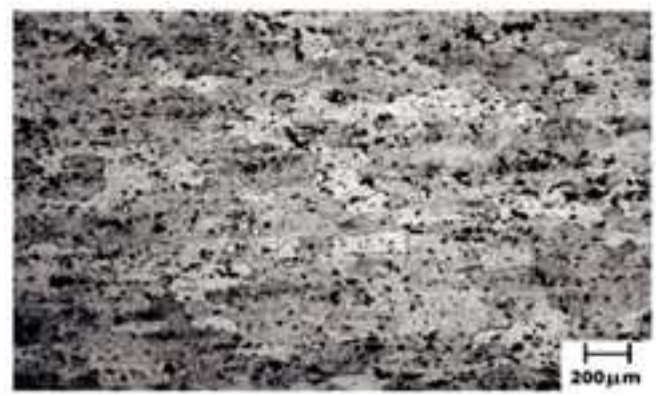

Figure5: Microstructures of base materials AA6061

\section{Figure 7: Friction stir welded part Al-Al}

\section{CONCLUSION}

From the experiments and the study conducted on the friction stir welding of dissimilar aluminium alloy 6061 to $\mathrm{Cu}$, the following conclusions are drawn.

Friction stir welding can produce defect free butt welds, between AA6061-Cu plates, with a joint efficiency of around $95 \%$ (base on the yield strength of the softer material i.e. AA6061).

The weld joints were stronger than the softer base material, and the tensile failures occur in the heataffected zone of the alloy 6061.The friction stir welding process parameters were optimized, with respect to tensile strength of the

Joint and the optimum level of settings were found. The optimum levels of the rotational speed, transverse speed, and the ratio of shoulder diameter to pin diameter (D/d) are $900 \mathrm{rpm}, 15 \mathrm{~mm} / \mathrm{min}$ and 2.5 respectively.

The current study shows that sound butt welded joints between AA6061 and $\mathrm{Cu}$ materials can be made using friction stir welding, with a joint efficiency of $95 \%$ (based on the yield strength of the softer material i.e. AA6061). It is to be noted that fusion welding of 
these dissimilar aluminium alloys is not feasible due to severe solidification cracking.

\section{References}

1. Amancio-Filho, S. T., Sheikhi, S., Dos Santos, J. F., Bolfarini, C. "Preliminary study on the microstructure and mechanical properties of dissimilar friction stir welds in aircraft aluminium alloys 2024-T351 and 6056-T4", Journal of materials processing technology, Vol. 206, pp. 132-142.

2. ASTM E8/E8M - 09. "Standard test methods for tension testing of metallic materials1", ASTM International, 3 July.

3. Atallah, M. M. and Hanadi G Salem. "Friction stir welding parameters: a tool for controlling abnormal grain growth during subsequent heat treatment", Materials Science Engineering, Vol. 391, pp.51-59.

4. Baeslack III, W. A., Jata, K. V., Lienert, T. J. "Structure, properties and fracture of friction stir welds in a high-temperature $\mathrm{Al}-8.5 \mathrm{Fe}-1.3 \mathrm{~V}-1.7 \mathrm{Si}$ alloy (AA-8009)", J Mater sci., Vol. 41, pp. 2939 2951.

5. Bala Srinivasan, P., Dietzel, W., Zettler, R., dos Santos, J. F., Sivan, V. "Stress corrosion cracking susceptibility of friction stir welded AA7075AA6056 dissimilar joint", Materials Science and Engineering A, Vol. 392, pp. 292-300.Aluminum
Alloy 6013", Metallurgical and materials transactions B, Vol. 33B, pp. 489-498.

6. Bob Irving. "Scandium Places Aluminium Welding on a New Plateau", Welding Journal, 76, pp. 53-57.

7. Brenneccke, M. W. "Electron beam welded heavy gage aluminium alloy 2219", Welding Journal, January, pp. 28-40s.

8. Bruni, C., Forcellese, A., Gabrielli, F. and Simoncini M. "Effect of the /v ratio and sheet thickness on mechanical properties of magnesium alloy FSWed joints", Int J Mater Form, Suppl 1, Vol. 3. Pp.1007-1010.

9. Cavaliere, P., De Santis, A., Panella, F., Squillace, A. "Effect of welding parameters on mechanical and micro structural properties of dissimilar AA6082-AA2024 joints produced by friction stir welding" Materials and Design, Vol. 30, pp. 609616.

10. Cavaliere, P., Panella, F. "Effect of tool position on the fatigue properties of dissimilar 2024-7075 sheets joined by friction stir welding", Journal of Materials Processing Technology, Vol. 206, pp. 249-255.

11. Chen, T. and Lin, W. B. "Optimal FSW process parameters for interface and welded zone toughness of dissimilar metals. 